\title{
DOSSIẾ
}

Sociologias, Porto Alegre, ano 16, no 37, set/dez 2014, p. 144-175

\section{Consumos de classe média num Portugal em crise: cultura, lazer e tecnologias de informação}

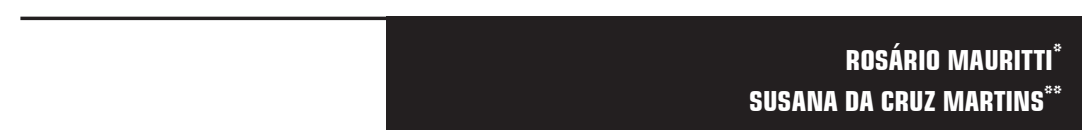

\section{Resumo}

Este artigo dá conta de configurações de práticas culturais e de consumo e estilos de vida, tendo por referência o momento de contração das condições sociais e econômicas atuais, em Portugal. Um dos traços mais marcantes das transformações a que estamos a assistir está ligado com o aumento de desigualdades sociais no acesso a bens e a recursos característicos de uma sociedade do conhecimento e de uso mais intensificado de tecnologias de informação e comunicação. Contrariando algumas das visões sobre a irrelevância de uma conceção das classes sociais, pretende-se desenvolver uma perspetiva de "classe média", através da identificação de princípios sociais padronizados de diferenciação estrutural de recursos e oportunidades. Esta aproximação teórica-analítica à classe média pretende ainda dar conta das repercussões de um contexto economicamente recessivo e de aprofundamento de desigualdades, situando esse segmento social. Esta proposta tem como base empírica os resultados de um estudo (online) aos rendimentos e consumos das famílias de classe média em Portugal, promovido no Centro de Investigação e Estudos de Sociologia do Instituto Universitário de Lisboa (CIES-IUL) no último trimestre de 2012, e desenvolvido no quadro do Projeto Pensar o futuro e encontrar novas perspetivas para a promoção sustentada do bem-estar e qualidade de vida.

Palavras-chave: Classe média. Padrões de renda. Consumos. Práticas culturais e TIC.

Instituto Universitário de Lisboa (ISCTE-IUL), Portugal

** Instituto Universitário de Lisboa (ISCTE-IUL), Portugal 
Middle class consumption in a Portugal in crisis: culture, leisure and information technology

\begin{abstract}
This paper deals with cultural and consumption practices and lifestyles, in the context of the current social and economic downturn in Portugal. One of the most striking features of the ongoing transformations is connected with the increase of social inequalities regarding the access to goods and other resources that characterize a knowledge society and to the greater use of information and communication technologies. Contrary to some views about the irrelevance of a conception of social classes, we intend to develop a perspective of "middle class", by identifying standardized social principles for structural differentiation of resources and opportunities. This theoretical-analytical approach to the middle class also aims to comprehend the repercussions of a context of economic recession and deepening inequalities, situating this social segment. This proposal is based on the empirical results of a (online) study on the income and consumption of middle-class families in Portugal, carried out at the Centre for Research and Studies in Sociology, Lisbon University Institute (CIES-IUL) in the last quarter of 2012 and developed as part of the Project Thinking the future and finding new prospects for the sustained promotion of well-being and quality of life.
\end{abstract}

Keywords: Middle class. Income standards. Consumption. Cultural practices and ICT. 
Sociologias, Porto Alegre, ano 16, no 37, set/dez 2014, p. 144-175

1 Classe média portuguesa numa sociedade globalizada e do conhecimento

Enquadramento e objetivos

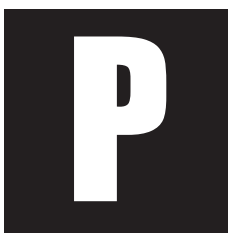

ortugal tem experimentado nos últimos anos, e de forma mais intensa depois das medidas de austeridade justificadas politicamente pelo Programa de Ajustamento Económico e Financeiro ${ }^{1}$ iniciado em 2011, processos recessivos nas finanças e na economia, refletindo-se nas condições de vida dos indivíduos e das famílias, e pondo em causa a manutenção de padrões de consumo e de acesso à cultura. Os dados do Inquérito às Condições de Vida e Rendimento (EU-SILC), implementado em Portugal em 2013 pelo Instituto Nacional de Estatística (INE), são disso uma boa ilustração.

Neste país, um dos mais desiguais da Europa, tem-se assistido à descida do emprego, à flexibilização das leis laborais, ao aumento de fluxos de emigração (com valores só comparáveis com os dos anos 60 do século passado), à permanência de traços de um modelo econômico baseado em baixos salários, à perda de instrumentos de política social que garantam a salvaguarda de riscos sociais, entre outras dimensões de interpelação do momento atual (Carmo; Cantante, 2014; Botelho et al., 2014). Estes são aspetos equacionados num quadro de forte diminuição de investimento público e privado e, sobretudo, de uma aparente ausência de soluções alternativas, com reflexos na universalização de mecanismos de proteção social, de saúde e de educação.

Tal cenário é, assim, ele próprio, propulsor da intensificação dessas desigualdades sociais e econômicas, no sentido de uma tendência para a polarização das condições materiais de vida (Rodrigues, 2012; Cattani,

\footnotetext{
${ }^{1}$ Monitorizado pela Troika - formação constituída pela Comissão Europeia, Banco Central Europeu (BCE) e Fundo Monetário Internacional (FMI), como condição para a ajuda financeira solicitada pelo Governo português em 7de abril de 2011.
} 
2007). Isto, especialmente, tendo em conta que os ganhos obtidos numa relativa atenuação das desigualdades - que teve lugar entre 2003 e 2009, embora sem efeitos na alteração da posição do país no conjunto da União Europeia - foram sobretudo devidos à melhoria das condições de vida dos mais pobres (INE, 2010; Rodrigues, 2012). Suscita-se a este propósito uma multiplicação de análises que apontam para um bloqueamento e uma crescente proletarização dos posicionamentos sociais intermédios, ditos de classe média (Carmo, 2013; Estanque, 2003 e 2012; Matos; Domingos, 2012; Santos, 2011). Um pouco à semelhança do que sucede no Brasil, este segmento integrará os emergentes da nova classe média, apresentando caraterísticas que nos permitem integrar nesta classe, alargando-a e dando conta de um processo de mobilidade à conta destes batalhadores (Souza, 2011).

O presente artigo tem, assim, como objetivo produzir um conjunto de análises, teórica e empiricamente sustentadas, sobre as circunstâncias presentes e as alternativas que os indivíduos e famílias de classe média declaram para fazer face ao quadro da atual crise económica e social em Portugal. A análise desenvolvida, tal como veremos adiante, envolve um conjunto social que, embora internamente diferenciado, se demarca do todo da sociedade portuguesa nos seus traços de favorecimento relativo: em termos de perfis qualificacionais, padrões de renda, orientações de práticas culturais, de consumo e estilos de vida (Bourdieu, 1979; Markowitz, 2011). Concretamente, se pretende analisar como é que os indivíduos e famílias com condições de adaptabilidade melhoradas estão percecionando os efeitos da recessão econômica e do ambiente de incerteza social que se instalou no país, nas avaliações que fazem sobre ajustamentos/manutenção de orientações de consumo lúdico e práticas de lazer.

\subsection{Orientações teórico-analíticas}

A operacionalização do conceito classe média é sobejamente considerada e levanta problemas teóricos e operatórios relevantes enquanto 
categoria de estudo (Eder, 1995). A análise procura identificar a pluralidade de contextos sociais, culturais e econômicos que a enquadram, tendo em vista ainda alguns dos padrões e princípios de coesão social, que têm prevalecido nas sociedades ocidentais contemporâneas (Sen, 2009), bem como, algumas das suas práticas culturais e de relação com as tecnologias.

No momento atual, certas propriedades da globalização têm afetado alguns dos efeitos de desigualdade, nomeadamente entre os países desenvolvidos industrializados (Milanovic, 2006; Piketty, 2013). Os processos intensos de mudança em diferentes níveis e esferas de participação social, assim como a incerteza crescente a eles associada têm sido um objeto de estudo recorrente.

Poder-se-á dizer que tais mudanças e incertezas que vivenciamos, afetando uma boa parte das condições sociais da nossa existência enquanto cidadãos, não são em si mesmas experiências sociais recentes. Numa discussão já com algumas décadas,várias tradições teóricas as vêm sublinhando como parte do risco global da individualização (Beck, 2004) da globalização e reflexividade institucionais (Giddens, 2000). Implicando que muitos dos processos sociais das sociedades contemporâneas sejam caraterizados pela sua fluidez (Bauman, 2001) e diferenciados pela dominância da cultura de virtualidade real, em que as tecnologias da informação e comunicação (TIC) e o funcionamento em rede são instrumentos nevrálgicos (Castells, 2002). Mas, como refere criticamente Will Atkinson (2010), algumas destas propostas têm secundarizado o conceito de classe social, tomando-o como ineficaz para captar a mudança social. Curiosamente, em alguns dos trabalhos anteriormente referidos, nomeadamente os de Ulrich Beck e de Anthony Giddens, a classe média é o único segmento de classe que se identifica como referência empírica. Isto deve-se, em parte, ao seu protagonismo social nesses processos, suportado por recursos qualificacionais e competências de autonomia, orientações e práticas e estilos de vida, 
que lhes conferem capacidades reflexivas reforçadas no quadro da estrutura social dessas sociedades (Costa; Machado; Almeida, 2007).

Numa posição que contraria algumas das visões dominantes sobre a irrelevância analítica das classes sociais (cf. Atkinson, 2010), a nossa proposta fundamenta-se na compreensão e interpretação das desigualdades sociais através de uma sociologia das classes sociais (Costa et al., 2000; Mauritti; Martins, 2012; Martins; Mauritti; Costa, 2007; Mauritti; Nunes, 2013). Como afirma Erik Olin Wright (1997), as classes contam.

Nessa orientação situam-se algumas das abordagens que se têm afirmado, tanto na evocação teórica do conceito de classe média como na sua aplicação, no âmbito de pesquisas que tentam, no momento, captar os efeitos da crise no aprofundamento de desigualdades sociais. Particularmente, os estudos focados sobre a sociedade portuguesa associam a estes processos repercussões de contornos especialmente marcantes na contenção e delapidação de recursos e oportunidades (Carmo, 2012; Costa, 2012; Estanque, 2009 e 2012). Nesta linha analítica, é igualmente pertinente e interessante analisar processos complexos de diferenciação e desigualdade que atravessam segmentos de classe (cf. Scalon, 2011). Na visão que assumimos neste artigo, não deixamos ainda de ter presente que, lado a lado com as classes sociais, existe uma multiplicidade de mecanismos, cada um deles sediado em relações específicas de dominação simbólica, identitária ou política (Capucha 2005; Costa et al., 2000; Estanque, 2009, p. 121).

$\mathrm{O}$ indicador de classe ou indicador socioprofissional aqui utilizado foi proposto por Almeida Costa e Machado (Costa, 1999; Machado et al., 2003; Costa; Machado; Almeida, 2007); uma equipa de pesquisadores do Instituto Universitário de Lisboa (ISCTE-IUL). Nas soluções encontradas por estes autores, se estabelece um diálogo direto com quatro alternativas teóricas e operatórias: as categorias socioprofissionais francesas (Desrosières; Thévenot, 1988); os esquemas de classes profissionais de 
Sociologias, Porto Alegre, ano 16, no 37, set/dez 2014, p. 144-175

John H. Goldthorpe (1980) e Erikson e Goldthorpe (1993); e as tipologias de lugares de classe de Erik Olin Wright $(1978,1985,1997)$.

A construção da matriz ACM inclui como variáveis principais a profissão (operacionalizada por referência à nomenclatura internacional de classificação de profissões: ISCO) e a situação na profissão (onde se distingue o patrão com empregados, o trabalhador independente/isolado e os trabalhadores por conta de outrem). Além disso, de forma complementar, inclui informação sobre a condição socioeconômica, os perfis de qualificação profissional, a posição na hierarquia e o exercício de autoridade, bem como o setor de atividade econômica ${ }^{2}$. Essas dimensões associadas na construção do indicador socioprofissional (ou de classe social) conferem-lhe, assim, uma capacidade analítica reforçada na abordagem de processos de desigualdade e diferenciação social.

Como referido atrás, este artigo, especificamente, desenvolve uma focagem nos segmentos de classe média, internamente diferenciados nas suas características estruturais, mas que partilham entre si posicionamentos sociais melhorados. E portanto, segmementos menos presentes nos estudos que enfatizam as desigualdades e o retraimento social e econômiCo, uma vez que se supõe que serão dos menos afetados pela crise que se vivencia hoje, de forma pronunciada, na sociedade portuguesa. Em que medida também esses segmentos de classe estão a ser afetados pelo ambiente de crise que afeta o país? É o que se pretende analisar neste artigo.

\section{Levantamento às classes médias}

No plano empírico-substantivo, a análise que se apresenta tem por referência os resultados de um levantamento (online) aos rendimentos

\footnotetext{
2 Para uma clarificação mais detalhada do modo de construção deste indicador e de outros relacionados, consulte Costa (2008 [1999], p. 223-241).
}

http://dx.doi.org/10.1590/15174522-016003706 
e consumos das famílias de classe média em Portugal, promovido pelo Centro de Investigação e Estudos de Sociologia do Instituto Universitário de Lisboa (CIES-IUL), no último trimestre de 2012. Concretamente, cerca de um mês após as manifestações de 15 de setembro desse ano, que sucederam de norte a sul do país. Portanto, num contexto de forte contestação e mobilização cívica, marcado pela implementação de medidas de aprofundamento da austeridade tuteladas pela Troika e em véspera da apresentação do Orçamento de Estado para 2013³, com efeitos negativos no crescimento sem precedentes do desemprego (INE, 2012) e na diminuição significativa de prestações sociais que se davam como garantidas.

Pensar o futuro e encontrar novas perspetivas para a promoção sustentada do bem-estar e qualidade de vida, foi com este mote que dirigimos um convite "fechado" 4 a sensivelmente 2500 portugueses, cujos emails nos foram facultados num processo de passa-palavra entre colegas, amigos e amigos de amigos - trabalhadores do setor público e privado, inseridos em diferentes áreas econômicas, especialmente dirigentes, profissionais intelectuais e científicos e quadros técnicos e superiores --, dos quais perto de $40 \%$ acederam em participar.

Concretamente, o estudo procura responder a estas necessidades de informação, disponibilizando um elenco de questões abordadas nos questionários que remetem para os seguintes conteúdos analíticos:

1. Caracterização das condições econômicas e padrões de renda, incluindo elementos sobre situação de endividamento e comportamentos de poupança;

\footnotetext{
${ }^{3}$ Lei n. ${ }^{\circ}$ 66-B/2012. Disponível em: <https://m6.ama.pt/docs/LOE2013.pdf>.

4 "Fechado" no sentido em que o acesso e preenchimento online do questionário teve como requisito prévio a receção de um email com convite à participação e senha para acessamento (login). As respostas, uma vez submetidas, foram transferidas de forma automática para uma base de dados autónoma, extraída em formato SPSS, garantindo desta forma a anonimização dos dados.
} 
2. Redes pessoais e sociais e recursos privados para fazer face a encargos financeiros não previstos;

3. Evolução dos consumos nos últimos 12 meses, face ao momento de preenchimento do questionário, por categorias de produtos e serviços;

4. Estratégias de adaptação num cenário de incerteza e diminuição da capacidade de consumo, associadas a preferências de marca/serviço e custos;

5. Perceções sobre bem-estar e qualidade de vida e posicionamentos em relação ao futuro;

6. Elementos de caracterização sociodemográfica e profissional dos indivíduos e famílias abrangidos no estudo.

Neste artigo, enfatizam-se alguns dos resultados integrados nas dimensões de análise das alíneas um, três, cinco e seis. Retomando algumas linhas de caracterização do conjunto aqui em análise, avançadas num primeiro momento de divulgação de resultados: os respondentes ao levantamento em referência

[S]e demarcam no conjunto da população portuguesa como um todo pelos seus altos perfis qualificacionais (85\% têm pelo menos o grau de licenciatura). A larga maioria exerce uma atividade profissional a tempo integral (81\%) que se consubstancia de forma muito incidente, tendo por referência o indicador socioprofissional utilizado, numa inserção nos segmentos dos profissionais técnicos e de enquadramento (PTE). Estes, aqui internamente diferenciados nos agrupamentos dos profissionais, intelectuais e científicos e dos quadros técnicos e de enquadramento (respetivamente com representações que envolvem cerca de $38 \%$ e $31 \%$ do conjunto), e nos posicionamentos de topo na hierarquia social, dos empresários e dirigentes (11\%) e dos profissionais liberais (5\%) (Mauritti, 2012).

Como argumentaremos adiante, em convergência com tais traços de favorecimento material e simbólico, os segmentos em análise se distin-

http://dx.doi.org/10.1590/15174522-016003706 
guem ainda em relação a outros, dominantes na sociedade portuguesa, pelos consumos que protagonizam, com todas as suas implicações e manifestações nas várias esferas da vida social, profissional e familiar (aliás como já tinha ficado nítido em Martins, Mauritti e Costa, 2007). Mais do que qualquer outro, é nestes conjuntos da população que se materializam, com maior intensidade, quantitativa e qualitativa, consumos lúdicos, culturais, estéticos, desportivos, tecnológicos e educativos.

\section{Condições econômicas e perfis de renda}

Segundo os Censos 2011 (INE), atualmente em Portugal pouco mais de um terço da população concluiu pelo menos o ensino secundário ${ }^{5}$. As estimativas do INE indicam que, também nesse ano, a renda média anual dos portugueses com ensino superior andava perto dos 19.900 euros, sendo o valor correspondente para os que tinham o ensino secundário de 11.900 euros $^{6}$. O confronto destas informações genéricas com os elementos apresentados na Figura 1 permitem, pois, posicionar o conjunto aqui em análise num perfil econômico e social de clara distinção.

No total, $14 \%$ dos inquiridos obtiveram um doutorado; cerca de $20 \%$ concretizaram o mestrado e pouco mais de 50\% têm no máximo a licenciatura. O contraste com o todo nacional é muito acentuado: mesmo na classe dos trabalhadores assalariados de base dos serviços administrativos, comerciais, pessoais e de segurança (os empregados executantes) essa diferenciação é notória, muito embora este seja o segmento - como seria expectável - com um perfil relativo menos definido pelas qualificações de topo, já que mais de metade tem como escolaridade o ensino médio (secundário).

${ }^{5}$ Grau equivalente ao ensino médio da educação básica no Brasil, correspondendo ao ISCED/CITE 3 tal como consta na Classificação Internacional Tipo de Educação (CITE), aprovada pela UNESCO. ${ }^{6}$ Fonte: PORDATA (atualização: 2012-12-05). Ter em conta que um euro equivale sensivelmente a três reais. 
Sociologias, Porto Alegre, ano 16, no 37, set/dez 2014, p. 144-175

A análise combinada dos indicadores socioeducacionais e socioprofissionais permite mapear de forma mais precisa estratégias e possibilidades diferenciadas no acesso a oportunidades, recursos e recompensas. $\mathrm{Na}$ elite econômica aqui em presença, onde se posicionam os empresários e dirigentes (ED), a incidência de qualificações se situa nos níveis de licenciatura e mestrado. Esta distribuição é também característica dos profissionais liberais $(\mathrm{PL})$ : trabalhadores que exercem atividades periciais por conta própria, por vezes no âmbito do autoemprego, em face da carência de oferta de trabalho qualificado no assalariamento. Nas frações de classe que compõem os profissionais técnicos e de enquadramento (PTE) - onde a escolaridade é um elemento nuclear, refletindo muitas vezes processos de reprodução social e cultural, determinante na caracterização desta categoria -, os especialistas das profissões intelectuais e científicas, como subcategoria destes, se destacam, notoriamente, nos níveis de pós-graduação, enquanto os quadros técnicos e de enquadramento intermédio incidem, sobretudo, no grau de licenciatura. 


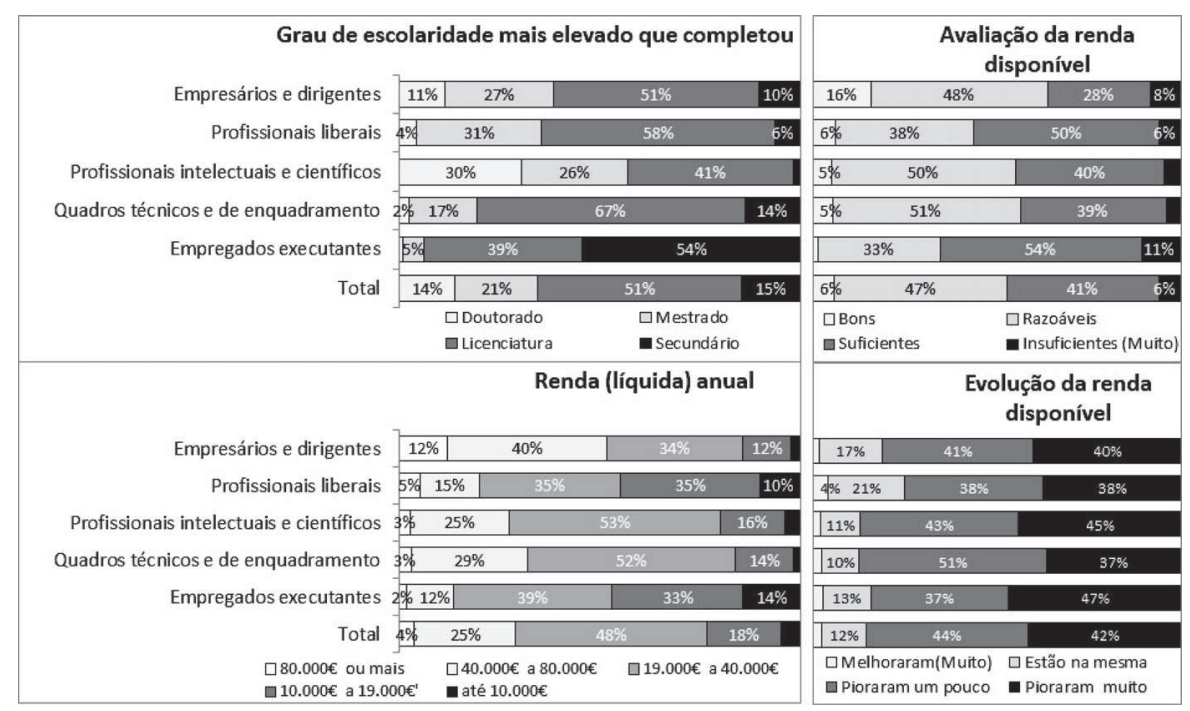

Figura 1. Classes médias, perfis de qualificação e de renda em Portugal (\%)

Qui-quadrado significativo $\mathrm{p} \leq 0,000 ; \mathrm{N}=992$.

Nota: Para efeitos da análise aqui desenvolvida, consideramos apenas os respondentes que têm como nível de escolaridade pelo menos o ensino medio/secundário ( $N=992$; num total original de 1001 questionários com respostas válidas).

Fonte: CIES-IUL (2012), IRC - Inquérito aos Rendimentos e Consumos.

A abordagem combinada do indicador socioprofissional com os escalões de renda líquida anual (Figura1) confere pertinência à orientação analítica de diferenciação da velha classe média, reconhecida nas análises clássicas, aqui assinalada no conjunto dos PL. Em contraste com as frações da burguesia empresarial e dirigente, aqueles denotam alguma polarização interna das suas condições - embora no seu todo não manifestem, senão de forma muito marginal, situações de privação material. Nos dois segmentos que integram os PTE, os assalariados técnicos e profissionais de nível intermédio das empresas e da administração ganham alguns pontos 
(ou euros) na comparação com os seus pares que se posicionam nas profissões de elite intelectual e científica. Quanto aos empregados executantes (EE), apresentam um perfil muito próximo do dos $\mathrm{PL}$, ainda que com presença mais discreta nos escalões de renda de topo e mais incidente nos baixos e intermédios.

Nesta conformidade, não é propriamente surpresa que sejam quase residuais os que, na avaliação da situação do agregado familiar relativamente à renda disponível para fazer face às despesas e encargos mensais, assumam uma situação de insuficiência de renda ( $6 \%$ do total). As oscilações nestas apreciações são, contudo, estatística e analiticamente muito significativas.

Os assalariados de base dos serviços, logo seguidos de forma algo paradoxal (mas que na conjuntura atual e dado o perfil do tecido econômico do país se torna compreensível) pelos empresários e dirigentes, são os que declaram com mais frequência maiores dificuldades.

Nos itens originais dispostos nas opções de resposta à pergunta sobre a situação de renda, os dois posicionamentos de classe elegeram sensivelmente na mesma proporção (3\%) a opção de resposta muito insuficientes, não garantem a subsistência e regularmente recorremos ao apoio de familiares, amigos ou outros para alimentação e outros bens/serviços essenciais; outros 8\% de EE (de um total de 11\% que assinalam sua situação de renda insuficiente) e $6 \%$ (ED e PL) denotam uma insuficiência mais moderada: a subsistência é assegurada com forte contenção dos gastos mesmo com produtos básicos, e por vezes compramos fiado. São, apesar de tudo, experiências muito minoritárias neste conjunto, mas que não deixam de abrir um pouco a visão sobre o que poderá ser o quadro de referência alargado na população portuguesa como um todo, especialmente, se tivermos em atenção que este é um conjunto que se destaca pelos seus recursos de algum favorecimento na comparação com o todo nacional (cf. Almeida e outros, 2007). 
Não temos aqui espaço para aprofundar estes dados, como seria desejável. Podemos adiantar brevemente que, nas avaliações sobre a situação de renda, os escalóes que mais denotam uma evolução negativa, com expressão muito significativa, correspondem aos segmentos até 10.000 euros e de 10.000 a 19.000 euros (precisamente os patamares de renda onde se encontra a maioria dos portugueses); incidem nas idades acimas dos 45 anos; nos casais com crianças dependentes e nos divorciados; nos indivíduos que não exercem uma atividade profissional mas já exerceram; no trabalho assalariado.

Estas apreciações, que dão conta do agravamento das condições de vida, são ainda reforçadas na avaliação sobre a evolução de renda (líquida) disponível no agregado para fazer face a despesas pessoais e familiares, nos últimos doze meses. No total, sensivelmente $85 \%$ percecionam um agravamento moderado (44\%) ou muito expressivo $(42 \%)$ das suas condições de renda. De notar também que a experiência de pauperização progressiva é percecionada com maior acuidade pelos segmentos de assalariamento, embora também no lado do capital ela seja evidente.

No leque de fatores assinalados na Figura 2, como motivos principais para a contração da renda disponível, emergem categorias que refletem as políticas de combate ao défice, consubstanciadas no aumento de impostos (74\%) e no incremento do custo de vida (nomeadamente por via da atualização das taxas de IVA ${ }^{7}$ e do consequente aumento generalizado dos preços de produtos de alimentação básica e da energia e combustí-

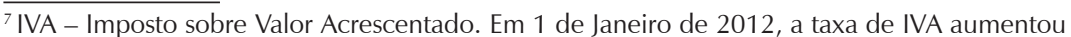
de $21 \%$ para $23 \%$. Além disso, alguns produtos que antes eram taxados no mínimo (6\%), como a água engarrafada, bebidas e sobremesas lácteas e refrigerantes saltaram para a taxa normal (23\%). Outros como o café, a fruta em calda, as compotas, os óleos e margarinas, os frutos secos e aperitivos, produtos congelados e pré-congelados, assim como alimentos preparados como comida para bebé, sanduíches e sopas e refeições pronto a comer, etc. saltaram da taxa intermédia (13\%) para a normal (23\%).
} 
veis) (62\%). A estes juntam-se ainda, embora a alguma distância, a perda de benefícios sociais (38\%) e a diminuição do salário ou renda (25\%), muito transversais no setor privado (por via da redução das remunerações, perda do carro de empresa, restrições no celular, internet, prémios anuais, entre outros). O desemprego do próprio ou de um familiar (14\%) ou a quebra de vendas/prestações de serviços (subemprego, especialmente no segmento de profissionais liberais) (9\%) são declarações que dão conta de experiências que adquirem, igualmente, algum relevo. Todos estes indicadores acentuam, pois, a urgência de repensar intervenções sustentadas que, simultaneamente, permitam inverter a subida do desemprego e do subemprego, bem como prolongar os apoios sociais, sobre a forma de subsídios ou outros, para atenuar os riscos sociais que decorrem da quebra de laços laborais (INE 2011).

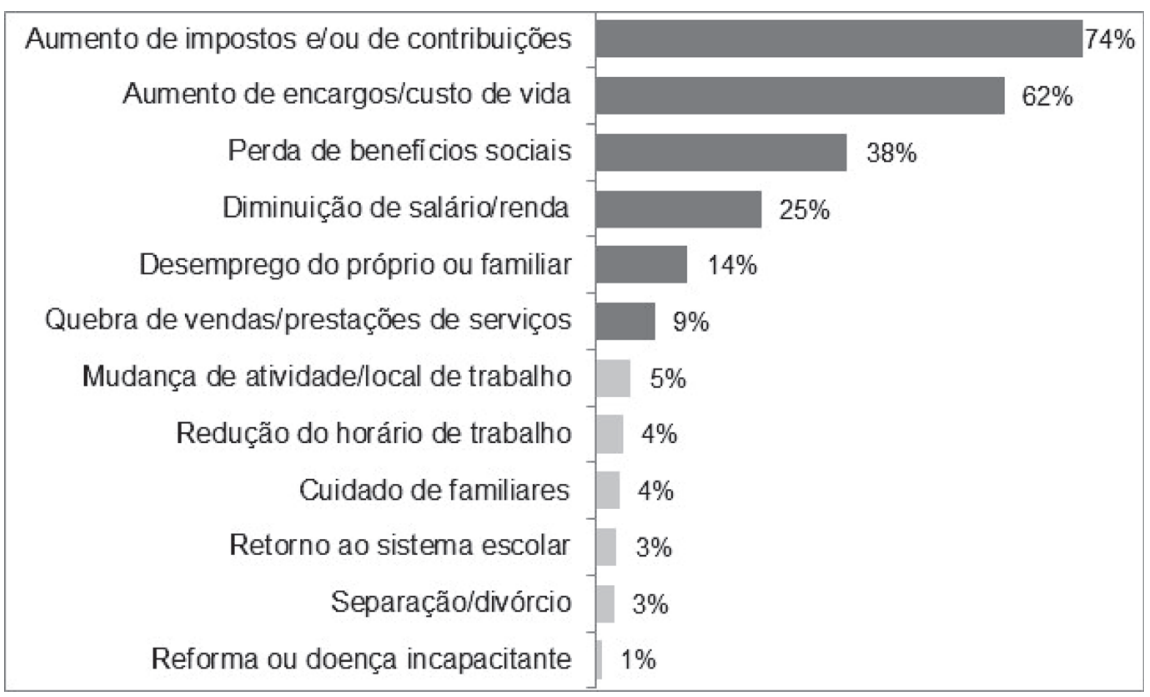

Figura 2. Razões apontadas para a diminuição da renda disponível(resposta múltipla) Fonte: CIES-IUL (2012), IRC - Inquérito aos Rendimentos e Consumos. 
Quotidianos e estilos de vida: orientações culturais e acesso à tecnologia

Os dados até agora apresentados sugerem a intensificação de alguma polarização das condições de vida entre posicionamentos sociais, que acolhem franjas de famílias e indivíduos ganhadores - incluindo aqui todos aqueles que indicam que têm conseguido fazer escolhas, no sentido de assegurar a manutenção do bem-estar e qualidade de vida, sem grandes roturas face ao passado recente -, e um polo crescente de perdedores, particularmente incidente nos setores de assalariamento. Esta polarização parece se acentuar num contexto de degradação das condições gerais de vida, impulsionada pela diminuição da renda disponível e pela quebra de laços identitários construídos nas relações de trabalho.

\subsection{Práticas de lazer, sociabilidades e orientações culturais}

A análise da renda disponível destas famílias, balizadas por condições materiais de favorecimento em comparação com a população portuguesa, sugere uma prevalência de situações de continuidade ou, pelo menos, de manutenção adaptada, relativamente a alguns vetores nucleares de bem-estar e qualidade de vida (Mauritti; Martins, 2012). Neste ponto, em particular, pretendemos analisar em que medida a autonomia relativa, face às condições gerais de retraimento econômico, das orientações de escolha e preferências, materializadas nas diversas componentes de consumos, é, ou não, manifesta também nas práticas de lazer, sociabilidades e orientações culturais destas famílias.

A Figura 3 apresenta um conjunto de indicadores que apoiam esta reflexão através da análise das perceções que os próprios têm sobre a frequência com que aderem a diversas orientações culturais e atividades de sociabilidade e lazer. A análise dá realce às relações sistemáticas entre 
a adesão às práticas, os perfis de escolaridade e os padrões de renda disponíveis nas famílias dos indivíduos da amostra.

Numa primeira leitura desses dados, ganham relevo práticas de consumo/lazer e consumo/necessidade e saúde consonantes com um universo simbólico e cultural que faz apelo à contenção de gastos, tendo em conta o constrangimento econômico e financeiro vivido. Passear por jardins e espaços públicos (pouco mais de $80 \%$ afirmam fazê-lo muitas/ algumas vezes); Fazer desporto ao ar livre (correr/fazer jogging, andar de bicicleta, etc.) (uma prática assumida por cerca de dois terços); Preparar 'marmita' para refeição fora de casa (mais de 50\%); Ir a museus e exposições (45\%), são atividades que este conjunto diz fazer com, pelo menos, alguma regularidade. Nestas orientações têm também relevo, mas pela negativa, ou pelo peso dos que têm ausência de tais práticas, Ir ao estádio ver um jogo profissional (perto de $2 / 3$ nunca o faz) ou Pedir livros na biblioteca (com $44 \%$ de respostas na opção «nunca»).

Estes itens de frequência dão-nos uma noção da perceção que estes sujeitos têm relativamente à sua mobilização nas atividades de tempos livres e orientações culturais referenciadas. Mas podemos supor que algumas das avaliações manifestadas relativamente à frequência das práticas incorporam também apreciações subjetivas que relacionam, de forma complexa, aspirações, expectativas e possibilidades de realização de consumos. Estes são, simultaneamente, diferenciados e diferenciadores, e explicados quer por dimensões de tipo estrutural (padrões de renda e condições materiais de vida, classe social, perfis educativos), quer de status. Estes últimos, podendo se expressar em orientações lúdicas que associam saúde e lazer, articuladas também com dimensões sociodemográficas (associadas com a idade, o sexo, tipos de alojamento familiar e contexto de residência; relações de conjugalidade, entre outras).

A relação dos indicadores de práticas de tempos livres e lazer e orientações culturais, tal como listado na figura 3, com os perfis de renda disponível, 
Sociologias, Porto Alegre, ano 16, no 37, set/dez 2014, p. 144-175

evidencia variações estatisticamente significativas. As excepções remetem apenas para dois itens, a saber: fazer desporto ao ar livre (na formulação original do indicador com a especificação: correr, fazer jogging, bicicleta, etc.) - uma prática, como referido atrás, com forte adesão - e requisitar livros, vídeos e outros afins na biblioteca, a qual no total de respondentes, dois quintos declaram nunca fazer - proporção que sobe para dois terços nos casos de renda mais elevada e desce, sensivelmente, quando focamos as práticas do conjunto com renda mais baixa, no seio do qual o recurso à biblioteca é uma prática com expressão (envolvendo quase metade dos sujeitos).

Outros itens também relacionados com práticas de leitura, como comprar livros com objetivos lúdicos, bem como comprar jornais ou revistas são, pelo contrário, os que denotam maior significância estatística em suas variações. Aqui a adesão de respostas positivas está, ainda de forma mais nítida, vinculada à escala de renda disponível: quanto mais elevados, também maior a disponibilidade para tais consumos. 


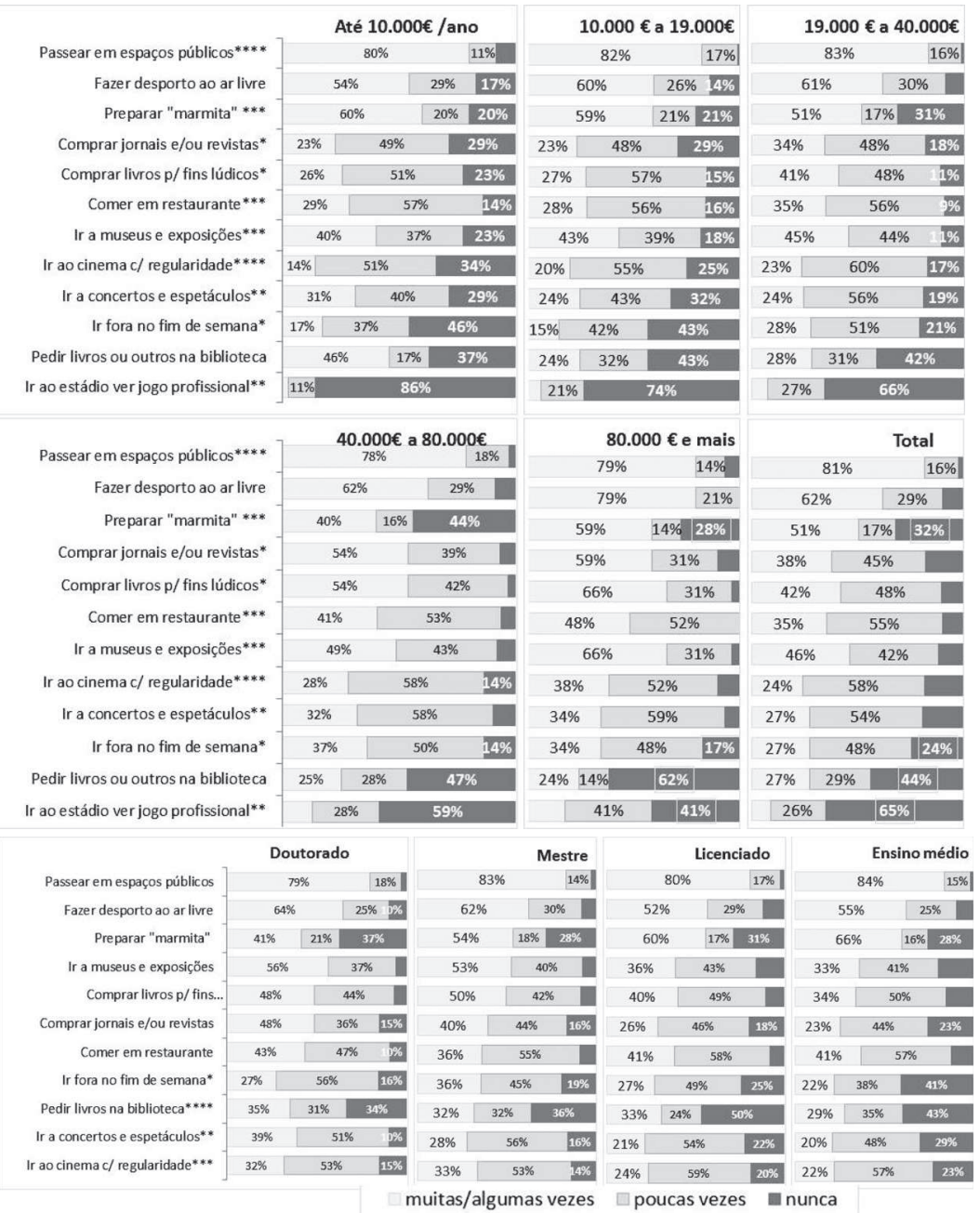

Figura3. Atividades de tempos livres e lazer e orientações culturais segundo perfil de renda e nível de escolaridade (\%)

Qui-quadrado significativo $\mathrm{p}<0,000 * 0.001 * * 0.005^{* * *} 0.05^{* * * *}$

Fonte: CIES-IUL (2012), IRC - Inquérito aos Rendimentos e Consumos. 
Já no conjunto de itens que equaciona práticas de sociabilidade e orientações culturais ligadas com o contexto da refeição, embora uma maioria dos respondentes realce o fato de ter aderido à moda, relativamente recente, de preparação em casa de refeições quotidianas que têm lugar em outros espaços (especialmente no trabalho ou na escola), têm também expressão aqueles que declaram nunca o fazer; aliás, numa proporção mais acentuada do que os que declaram nunca fazer refeições em restaurante ou similares. É curioso notar que, mesmo no seio dos conjuntos com renda disponível mais elevada, se nota alguma propensão de adesão à 'marmita' - aqui, hipoteticamente, com raiz não tanto em questões econômicas, mas mais na necessidade de controlo pessoal da dieta-saúde. Isto, muito provavelmente, tendo em vista a importância simbólica que atribuem à estética performativa da identidade corpórea, tão relevante nas interações quotidianas (Pais, 2006).

A análise destas orientações e práticas de consumo segundo perfis de escolaridade vem enfatizar as semelhanças, mais do que os traços de diferenciação, do conjunto aqui em referência: cuja delimitação, como assinalado atrás, teve como critério a seleção de indivíduos detentores de um diploma com equivalência ao ensino médio (secundário). Apenas em quatro itens (de um total de doze) são realçadas diferenciações significativas, nomeadamente: ir para fora no fim de semana; requisitar livros, vídeos e outros afins na biblioteca; ir a concertos e espetáculos e ir ao cinema com regularidade. Nestas quatro componentes de lazer e orientações culturais, a tendência de relação entre a adesão à prática e os recursos de escolaridade vai no sentido espectável: no geral, quanto maior o grau de escolaridade, maior a adesão. Aliás, apenas em dois itens, essa relação segue num sentido contrário: quanto mais baixo o grau de ensino, maior a adesão a passear em espaços públicos e preparar marmita.

Nestes protagonismos de práticas de consumo/cultura, se revelam algumas orientações que evidenciam a complexidade e diferenciação nas 
Sociologias, Porto Alegre, ano 16, no 37, set/dez 2014, p. 144-175

modalidades de adaptação e reação destes indivíduos e famílias face ao contexto envolvente, sugerindo alguma prevalência de decisões, relativamente a práticas de ocupação de tempos livres e lazer que, em grande medida, permanecem determinadas pelo gosto.

\subsection{Os eletrodomésticos e as TIC nos lares}

Com as transformações tecnológicas das últimas décadas, o espaço doméstico tem vindo a se reconfigurar à luz das suas atividades e tarefas quotidianas, bem como dos seus impactos nas relações e papéis familiares, entre outros aspetos da vida privada. Certo é que, nas décadas subsequentes à II Guerra Mundial, é nítida a introdução e massificação de eletrodomésticos nos lares, quer como substitutos de tarefas domésticas, quer na propagação de atividades lúdicas no interior desses espaços, como a televisão ou a música. Muitos desses dispositivos tecnológicos conheceram altos níveis de generalização, conferindo sentido a um acesso democratizado nas sociedades de consumo ocidentais.

Este movimento tecnológico cresceu de forma entrosada com a afirmação da sociedade do conhecimento (Stehr, 1994) e da informação (Lyon, 1992), fazendo entrar nos espaços domésticos tecnologias de informação e comunicação, e renovando conceções de comunicação, lazer e trabalho nesses espaços. Estas são peças incontornáveis na entrada plena neste tipo de sociedade (Castells, 2002 e 2005), na qual os indivíduos farão um uso cada vez mais alargado e continuado em casa, no trabalho, e nos espaços públicos em geral.

A Tabela 1 sintetiza informação, salientando um conjunto de indicadores respeitantes à posse de tecnologias e recurso a serviços de apoio doméstico por parte dos inquiridos e respetivas famílias, em função dos níveis de renda. Nesta abordagem, as tecnologias do lar são organizadas em dois tipos: um, respeitante aos equipamentos domésticos de uso mas- 
sificado; outro, respeitante à presença nestes agregados de novas tecnologias de comunicação, informação e lazer.

Em relação aos eletrodomésticos de uso corrente (como a máquina de lavar roupa, fogão, frigorífico/geladeira, forno), o elemento a reter é, de facto, a sua presença transversal, nas casas destas famílias. Ainda assim, denotando formas distintivas de apropriação e relação com o espaço doméstico, apenas no caso do fogão e do frigorífico (refrigerador ou geladeira) essa transversalidade não denota diferenciação por nível de renda. Algumas das tecnologias listadas - cuja presença no lar procura introduzir elementos de facilitação na gestão de tarefas domésticas - como é o caso da máquina de lavar louça, do congelador ou da máquina de secar roupa - marcam menor presença relativa em famílias que vivem num quadro de maior desafogo material. Para as quais, aliás, muitas vezes, contratar serviços de apoio doméstico é a solução que melhor responde às suas necessidades (no plano funcional e/ou simbólico).

Tabela 1. Eletrodomésticos, contratação de serviços domésticos e tecnologias nos agregados domésticospor nível de renda(\%)

\begin{tabular}{|c|c|c|c|c|c|c|}
\hline \multirow[b]{2}{*}{ Tecnologias e serviços do lar } & \multicolumn{5}{|c|}{ Níveis de renda } & \multirow[b]{2}{*}{ Total } \\
\hline & $\begin{array}{c}80.000 € \\
\text { ou mais }\end{array}$ & $\begin{array}{c}40.000 € \\
\mathrm{a} \\
80.000 €\end{array}$ & $\begin{array}{c}19.000 € \\
\mathrm{a} \\
40.000 €\end{array}$ & $\begin{array}{c}10.000 € \\
\mathrm{a} \\
19.000 €^{\prime}\end{array}$ & $\begin{array}{c}\text { até } \\
10.000 €\end{array}$ & \\
\hline & \multicolumn{5}{|c|}{ Equipamentos eletrodomésticos } & \\
\hline Máquina de lavar roupa*** & 100,0 & 99,0 & 99,2 & 95,5 & 94,3 & 98,3 \\
\hline Fogão ou placa & 93,1 & 95,8 & 96,1 & 94,8 & 88,6 & 95,3 \\
\hline Frigorífico (refrigerador ou geladeira) & 96,6 & 93,7 & 89,5 & 88,8 & 85,7 & 90,6 \\
\hline Forno elétrico ou a gás** & 77,1 & 84,3 & 90,1 & 93,7 & 82,8 & 89,1 \\
\hline Máquina de lavar loiça* & 37,1 & 63,4 & 82,6 & 95,3 & 89,7 & 80,6 \\
\hline Arca congeladora/combinado* & 54,3 & 43,3 & 63,9 & 78,0 & 82,8 & 64,1 \\
\hline Máquina de secar roupa* & 20,0 & 26,9 & 39,4 & 59,2 & 37,9 & 41,2 \\
\hline \multirow{3}{*}{$\begin{array}{l}\text { Aquecimento central* } \\
\text { Robot cozinha multifunções (bimby } \\
\text { e afins)* } \\
\text { Aparelho de ar-condicionado* }\end{array}$} & 8,6 & 12,7 & 26,4 & 31,4 & 44,8 & 25,1 \\
\hline & 34,5 & 32,5 & 20,4 & 14,2 & 11,4 & 22,5 \\
\hline & 27,6 & 35,6 & 17,1 & 9,0 & 5,7 & 20,2 \\
\hline
\end{tabular}

http://dx.doi.org/10.1590/15174522-016003706 
Continuação

\begin{tabular}{c|ccccc|c}
\hline & \multicolumn{5}{|c|}{ Contratação de serviços de apoio doméstico: } & \\
Sim e reforçou & 3,4 & 3,1 & 3,3 & 0,7 & 0,0 & 2,7 \\
Sim e mantém as mesmas condições & 58,6 & 43,5 & 26,7 & 7,5 & 0,0 & 27,5 \\
Sim mas diminuiu esses apoios & 10,3 & 26,2 & 21,5 & 8,2 & 2,9 & 19,0 \\
Hoje não, há 12 meses atrás sim & 6,9 & 6,3 & 4,7 & 5,2 & 0,0 & 5,1 \\
Não e não tinha há 12 meses atrás & 20,7 & 20,9 & 43,8 & 78,4 & 97,1 & 45,7 \\
\hline & Aparelhos eletrónicos disponíveis no agregado familiar & \\
Computador pessoal & 100,0 & 96,9 & 98,6 & 97,0 & 97,1 & 97,9 \\
Celular (Telefone móvel) & 93,1 & 96,3 & 94,5 & 95,5 & 94,3 & 95,1 \\
Acesso a Internet & 96,6 & 96,9 & 93,4 & 92,5 & 91,4 & 94,1 \\
Televisão por assinatura* & 93,1 & 94,8 & 89,0 & 83,6 & 60,0 & 88,3 \\
Telefone rede fixa* & 86,2 & 91,1 & 82,4 & 73,9 & 71,4 & 82,7 \\
Equipamento fotográfico** & 86,2 & 87,4 & 82,4 & 71,6 & 74,3 & 81,5 \\
Impressora/scanner* & 89,7 & 84,3 & 78,5 & 65,7 & 54,3 & 77,0 \\
Aparelhos de som/HiFi* & 86,2 & 78,0 & 71,1 & 55,2 & 31,4 & 68,8 \\
MP3 áudio** & 69,0 & 57,6 & 57,3 & 41,8 & 37,1 & 54,1 \\
Nintendo* & 55,2 & 51,8 & 50,7 & 29,9 & 25,7 & 46,3 \\
PlayStation/ PS Vita /Wii / Xbox / & 58,3 & 47,1 & 42,7 & 21,6 & 14,3 & 39,0 \\
Vídeo/Home Cinema* & 37,9 & 47,6 & 34,4 & 14,2 & 11,4 & 33,2 \\
Câmara de Vídeo* & 41,4 & 26,7 & 17,4 & 11,2 & 8,6 & 19,1 \\
Ipad / tablet* & & & & & &
\end{tabular}

Qui-quadrado significativo $p<0,000 * \mathrm{p}<0,001^{* *} \mathrm{p}<0,005^{* * *} \mathrm{p}<0,03 * * * *$

Fonte: CIES-IUL (2012), IRC - Inquérito aos Rendimentos e Consumos.

Neste indicador, relativo à contratação de serviços de apoio doméstico, se compara a situação presente com a vivida tem 12 meses atrás. O elemento mais significativo é que pouco mais de um quarto destas famílias alterou as condições que tinha (essa proporção é quase residual no caso do segmento inserido no patamar de renda acima de 80 mil euros). De resto, para os que alteraram a sua situação, o ajustamento introduzido, no geral, vai no sentido da diminuição dos apoios e menos na sua eliminação.

No segundo bloco de tecnologias do lar, onde as TIC têm uma posição central, o resultado mais saliente é a presença esmagadora do com- 
putador e da Internet e do celular (em quase 100\% dos lares), com uma importância que chega a ser superior à televisão - ainda imprescindível nos lares portugueses (Martins; Mauritti; Costa, 2007). Estes dados enfatizam, assim, de forma ainda mais intensa, mudanças significativas na utilização de TIC, que se registaram particularmente na viragem para o novo milénio. É impressionante a forma como, por exemplo, o uso diário de internet se generalizou nos últimos anos por toda a Europa. Relativamente a Portugal, 45\% dos indivíduos acede à Internet todos os dias, em 2012, enquanto em 2004 apenas 16\% o fazia (Martins, 2013).

Descobre-se nestes números da tabela 1 a importância muito generalizada, no conjunto em análise, de se estar conectado em contínuo e com diversos dispositivos de comunicação (visível, por exemplo, na prevalência do celular face ao telefone, do computador e da Internet face à TV; e no predomínio claro, também, da TV com assinatura).

Nos dados apresentados na Tabela1, os indivíduos e as famílias em que aquelas práticas e orientações, associadas aos usos de TIC, aparecem intensificadas têm melhores níveis de renda, mas nos itens citados (computador, celular e Internet), de uso mais transversal, as diferenciações entre diferentes segmentos de renda não são estatisticamente significativas, evidenciando a abrangência das práticas.

Alguns dos equipamentos disponíveis no lar (computador, internet, impressora, etc.) apoiam, também, o desenvolvimento, ou o prolongamento, de projetos ou atividades profissionais no espaço doméstico. Além disso, se observa em simultâneo a presença de outros equipamentos, como é o caso das consolas de jogos, cujo uso tem variações significativas na correlação com os níveis de renda destas famílias (tendencialmente, menos presentes nas famílias com menores níveis de renda), denotando a capacidade diferenciada destes agregados para a aquisição de equipamentos que intensificam as atividades lúdicas e de lazer no interior desse espaço. 
Sociologias, Porto Alegre, ano 16, no 37, set/dez 2014, p. 144-175

De resto, com exceção do computador, celular e Internet, as diferenças na presença de tecnologias eletrônicas entre os diversos segmentos de renda aqui em destaque são muito significativas. Apesar dessas diferenciações por níveis de renda, a presença, ou não, destes artigos eletrônicos mais associados às sociabilidades e ao lazer, que marcam em vagas ou modas algumas gerações, direcionados sobretudo a jovens e crianças (como a PlayStation, Nintendo, etc.) ou têm traduções em hobbies ou passa tempos (ver o exemplo dos aparelhos de som/HIFI, do MP3, da câmara de vídeo), configura também a sua expressão como necessidade incorporada. Decorre, daqui, que sua aquisição, quando extravasa as possibilidades de um orçamento familiar mais constrangido, seja, com alguma frequência, contornada através do acesso a créditos pessoais e instrumentos afins (Mauritti, 2013).

\section{Conclusões}

O estudo apresentado utiliza alguns dos principais focos analíticos no âmbito da sociologia das classes sociais, numa perspetiva relativamente abrangente - nomeadamente, a sua relação com recursos, práticas quotidianas e estilos de vida (cf. Martins; Mauritti; Costa, 2007; Mauritti; Martins, 2012) e, do ponto vista conceptual, o teste e a aplicabilidade da definição de segmentos daquilo que se tem vindo a consagrar como classe média. Esta, na delimitação aqui proposta, denota claramente condições de vida e orientações culturais de maior proteção e capacidade de enfrentar os constrangimentos estruturais empolados no atual contexto de crise, vivenciado intensamente em Portugal.

Os processos de recomposição estrutural aqui evocados sugerem que, mesmo no segmento de classe média, com maior capacidade reflexiva e melhores condições materiais e simbólicas de adaptação às mudan- 
ças em curso, a oportunidade de apropriação de uma parte da mais-valia social (Wright, 1997) se tornou cada vez mais difícil. Isto, quer porque os subsídios de lealdade, traduzíveis em oportunidade acrescidas de acesso a promoções e carreira, têm vindo a ser depurados à medida que aumenta $\mathrm{a}$ precariedade, atingindo os mais qualificados; quer ainda porque as recompensas salariais acima dos custos de obtenção e reprodução das qualificações também estão se deteriorando. Assim, tornou-se aqui incontornável discutir algumas das estratégias e capacidades para fazer face à contração das condições de vida. Nesta medida, a reflexão desenvolvida analisa de que forma os indivíduos e famílias posicionados no topo da classe média em Portugal estão a conseguir desenvolver estratégias de adaptação na gestão da renda disponível e das despesas realizadas para assegurar os seus estilos de vida, nomeadamente nas componentes de práticas culturais e nas sociabilidades. Os dados analisados evidenciam que, mesmo para estas famílias, a situação hoje parece estar em transmutação.

Nos perfis sociais e nos comportamentos e atitudes destes protagonismos de classe média, se evidenciam novos constrangimentos, muito empolados no discurso e na vivência material da crise no país. Contudo, estes coexistem com a expetativa de assegurar padrões de convivência pautados pela modernidade que atravessaram a sociedade portuguesa no último meio século, seja na componente ligada à incorporação crescente de tecnicidade, seja no aumento das qualificações, conhecimento e informação pericial no exercício de funções, seja ainda no alargamento de toda uma indústria de serviços lúdicos, culturais e estéticos, desportivos e de educação, entre outros.

$\mathrm{Na}$ última pergunta do questionário, todos os respondentes foram desafiados a fazer o seguinte balanço: Para terminar, fazendo um balanço geral, como avalia a situação do seu agregado familiar em termos de evolução do bem-estar e qualidade de vida? As possibilidades de resposta são 
Sociologias, Porto Alegre, ano 16, no 37, set/dez 2014, p. 144-175

apresentadas na figura 4, de forma agregada em relação às avaliações de melhoria (dada a pouca expressão de respostas nestes itens). No geral, dois terços declaram que a sua situação piorou $(74 \%$ dos indivíduos e famílias posicionados no escalão de renda entre 10.000 e 19.000 euros). E, apesar das variações notáveis entre os escalões de renda, o sentimento de insatisfação é geral. Embora, materialmente, tal como foi também possível demonstrar ao longo do artigo, o favorecimento relativo que demarca o conjunto se reflita na preponderância de estratégias de reconversão adaptativa por via da procura de soluções mais econômicas.

Não obstante, é igualmente verificado que se estão a afirmar distâncias entre aqueles que declaram uma maior capacidade para fazer escoIhas, mantendo no essencial a qualidade e estilos de vida, e os outros, em perda dessas possibilidades, com uma maior incidência nos segmentos do assalariamento e nos níveis de renda intermédios e elevados - envolvendo indivíduos e famílias que já integraram o mercado de trabalho há alguns anos, assumiram responsabilidades (incluso com a banca, nomeadamente para contrair casa própria ou em créditos ao consumo) (Banco de Portugal, 2011; Mauritti, 2013) e agora vêem-se sem condições para, de forma sustentada, prosseguir na construção de projetos de futuro. 


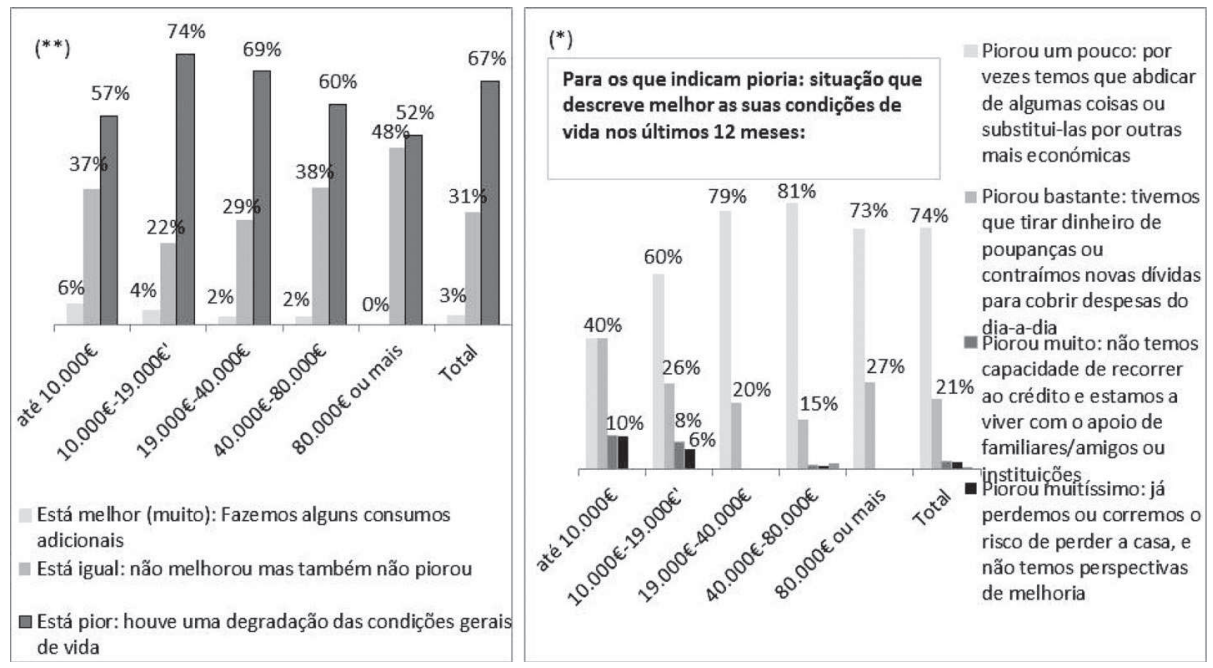

Figura 4. Avaliações sobre condições de bem-estar e qualidade de vida: comparação com há 12 meses atrás

Qui-quadrado significativo ${ }^{*} \mathrm{p}<0,000 ;{ }^{*} \mathrm{p}<0,01$.

Nos segmentos de renda mais baixa, encontramos já alguma presença de situações muito preocupantes, que implicaram a perda da casa para a banca por incumprimento $(10 \%$ dos posicionados no 10 escalão de renda), bem como vivem sob a dependência de solidariedade familiar e de instituições (outros 10\%).

Entre destituídos e remediados, uma nova realidade se tem vindo a materializar nas práticas de consumo e nas estratégias de criação e manutenção de relações sociais de diferenciação de status e consagração de estilos de vida distintivos nos posicionamentos sociais. Evidenciando-se que o capital cultural e simbólico, forte indutor de lógicas de identidade de demarcação diferenciadora (Bourdieu, 1979), se mantém por via das práticas culturais e de sociabilidade e de orientações de consumo, como um recurso de distinção de posições sociais. 
Rosário Mauritti. Professora no Instituto Universitário de Lisboa (ISCTE-IUL) e Pesquisadora no Centro de Investigação e Estudos de Sociologia (CIES-IUL). Email: Rosario. $\backslash$ mauritti@iscte.pt

Susana da Cruz Martins. Professora no Instituto Universitário de Lisboa (ISCTEIUL) e Pesquisadora no Centro de Investigação e Estudos de Sociologia (CIES-IUL). ${ }_{\text {susana.martins@iscte.pt }}$

\section{Referências}

1. ALMEIDA, J. F. Et al. Sociedade. In: REIS, A. (Org.).Portugal Anos 2000: Retrato de um País em Mudança.Mem Martins: Círculo de Leitores, 2007.p. 36-72.

2. ATKINSON, W. Same formula, different figures: change and persistence in class inequalities. Sociologia, Problemas e Práticas, n. 63, p.11-24, 2010.

3. BANCO DE PORTUGAL.Relatório do Inquérito à Literacia Financeira da População Portuguesa (2010). Lisboa: Banco de Portugal, Eurosistema. Disponível em: < http://www.clientebancario.bportugal.pt>. Acesso em2011.

4. BAUMAN, Z. The Individualized Society.Cambridge: Polity Press, 2001.

5. BECK, U. Risk Society: Towards a New Modernity. London: Sage Publications, 2004 [1992].

6. BOTELHO, M. C.et al. A mão esquerda e a mão direita do Estado português: que atuais tendências?. Observatório das Desigualdades, ISCTE-IUL, CIES-IUL, e-Working Paper. Disponível em: <http://wp.me/p4h6tu-ki>. Acesso em: 2014.

7. BOURDIEU, P. Razões Práticas: Sobre a teoria da acção.Oeiras: Celta Editora, 1997 .

8. BOURDIEU, P.La Distinction: Critique sociale du jugement. Paris: Éditions de Minuit, 1979

9. CAPUCHA, L. Desafios da Pobreza. Oeiras: Celta Editora, 2005.

10. CARMO, R. M. (Org.). Portugal uma Sociedade de Classes: Polarização Social e Vulnerabilidade. Lisboa: Edições 70/Le Monde Diplomátique, 2013.

11. CARMO, R. M. (Org). Desigualdades em Portugal: Problemas e propostas. Lisboa: Edições 70/Le Monde diplomatique, 2011.

12. CARMO, R. M.;CANTANTE, F. Precariedade, desemprego e proteção social: caminhos para a desigualdade? Observatório das Desigualdades. Lisboa: ISCTEIUL, CIES-IUL.e-Working Paper. Disponível em: <http://wp.me/p4h6tu-m3>. Acesso em: 2014. 
13. CASTELLS, M. A Sociedade em rede. In: CARDOSO, G.; COSTA, A. F.; CONCEIÇÃO, C. P.; GOMES, M. C. (Orgs.). A Sociedade em Rede em Portugal. Porto: Campo de Letras, 2005.p. 19-30.

14. CASTELLS, M. A Sociedade em Rede. A Era da Informação: Economia, sociedade e cultura.v. I. Lisboa: Fundação Calouste Gulbenkian, 2002.

15. CATTANI, A. D. Desigualdades Socioeconômicas: conceitos e problemas de pesquisa. Sociologias, Porto Alegre, ano 9, no 18, p. 74-99, jul./dez. 2007.

16. COSTA, A. F.Desigualdades Sociais Contemporâneas. Lisboa: Mundos Sociais, 2012.

17. COSTA, A. F.Sociedade de Bairro: Dinâmicas sociais da identidade cultural. Oeiras: Celta Editora, 1999.

18. COSTA et al.Classes sociais na Europa. Sociologia, Problemas e Práticas, n. 34, p. 9-46,2000.

19. COSTA, A. F.; MACHADO, F. L.; ALMEIDA, J. F.Classes sociais e recursos educativos: uma análise transnacional. In: COSTA, A. F.; MACHADO, F. L.; ÁVILA, P. (Org.).Sociedade do Conhecimento, Portugal no Contexto Europeu (Vol. II). Oeiras: CIES-ISCTE/ Celta Editora, 2007. p. 5-20.

20. DESROSIERES, A.; THEVENOT, L. Les catégories Socioprofessionnelles. Paris: La Découverte,1988.

21. EDER, K. Does social class matter in the study of social movements? A theory of middle-class radicalism.In:MAHEU, L. (Org.). Social Movements and Social Classes - The future of collective action.London: Sage, 1995.p 21-54.

22. ERIKSON, R.; GOLDTHORPE, J. H.The Constant Flux: A Study of ClassMobility in Industrial Societies. Oxford: Clarendon Press,1993.

23. ESTANQUE, E.A Classe Média: Ascensão e declínio. Lisboa: Fundação Francisco Manuel dos Santos, 2012.

24. ESTANQUE, E. Diferenças sociais de classe e conflitualidade socia. In: LAGES,M.; MATOS, A. T. (Org.). Portugal Intercultural: Razão e projecto. Lisboa: CEPCEP-Universidade Católica Portuguesa/ ACID, 2009.p. 123-176.

25. ESTANQUE, E. O 'efeito classe média': desigualdades e oportunidades no limiar do século XXI. In: CABRAL,M. V.;VALA, J.;FREIRE,A.(Org.). Desigualdades Sociais e Percepções de Justiça. Lisboa: Imprensa de Ciências Sociais ICS/ ISSP,2003.p 69-105.

26. GIDDENS, A.Vivernumasociedadepós-tradicional.In:BECK, U.;GIDDENS,A.; LASH, S. (Org.).Modernização Reflexiva: Política,tradição e estética no mundo moderno. Oeiras: Celta, 2000.p. 53-104. 
27. GOLDTHORPE, J. H. (Org). Social Mobility and Class Structure in Modern Britain.Oxford: Clarendon Press, 1980.

28. INE. Relatório A Evolução Recente do Desemprego (Documento provisório). Disponível em:<http://www.cnj.pt>.Acessoem: 11 jun. 2012.

29. INE.Rendimentos e Condições de Vida: Destaque à comunicação social. Disponível em:<http://www.cnj.pt> Acessoem: 11 jun. 2012.

30. INE.Sobre a Pobreza, as Desigualdades e a Privação Material. Lisboa: INE, 2010.

31. LYON, D.A Sociedade de Informação: Questões e Ilusões. Oeiras: Celta Editora, 1992.

32. MACHADO, F. L. et al. Classes sociais e estudantes universitários: origens, oportunidades e orientações.Revista Crítica de Ciências Sociais,n. 66, p. 45-80, 2003.

33. MARKOWITZ, M. A. Fazer Parte da Classe Média: Práticas discursivas em um bar no Rio de Janeiro e em um café em Buenos Aires, 2011. Tese (Doutorado em Antropologia)de Doutorado) - Instituto de Ciências Humanas e Filosofia da Universidade Federal Fluminense, Niterói,2011.

34. MARTINS, S. C. Schools and ICT resources: new educational challenges in European perspective. In: Proceedings of the EDULEARN13, 5th International Conference on Education and New Learning Technologies (Session: Emerging Technologies in Education), E-book,2013.

35. MARTINS, S. C.;MAURITTI, R.;COSTA, A. F. Padrões de vida na sociedade contemporânea.In:GUERREIRO, M. D.; CARDOSO, A. T.;CAPUCHA, L.(Org.).Quotidiano e Qualidade de Vida: Portugal no Contexto Europeu(vol. III). Lisboa: Celta Editora, 2007.p. 263-281.

36. MATOS, J. N.;DOMINGOS, N. (Org.).Novos Proletários. A precariedade entre a "classe média" em Portugal. Lisboa: Edições 70/Le Monde diplomatique, 2012.

37. MAURITTI, R. Rendimentos e inclusão financeira: comportamentos e orientações de frações de classe média. Plataforma Barómetro Social, 3a série, jun. 2013. Disponível em: < http://barometro.com.pt/archives/999>. Acesso em:jun. 2013.

38. MAURITTI, R. Processos de reconfiguração de estilos de vida: a classe média em perspetiva.Plataforma Barómetro Social. 5. - Série, dez. 2012.Disponível em: <http://barometro.com.pt/archives/791>. Acesso em: 5 dez. 2012.

39. MAURITTI, R.Viver Só: Mudança social e estilos de vida. Lisboa: Mundos Sociais, 2011. 
40. MAURITTI, R.; NUNES, N. Processos de recomposição social: continuidades e mudanças. In: CARMO, R. M. (Org.). Portugal uma Sociedade de Classes: Polarização Social e Vulnerabilidade, 2013.p.29-48.

41. MAURITTI, R.;MARTINS, S. C.Classe média, bem-estar e valores culturais: mudança e continuidade. In: SILVA, M. C.; AGUIAR, J. V. (Org.). Classes, Políticas e Culturas de Classe. V.N. Famalicão: Húmus,2012. p. 133-164.

42. MILANOVIC, B. Can We Discern the Effect of Globalization on Income Distribution? Evidence from Household Surveys, World Economics, v. 7, n. 1, 2006.

43. PAIS, J. M. Buscas de si: expressividades e identidades Juvenis. In: ALMEIDA, M. I. M.; FERNANDA, E. (Org.). Culturas Juvenis. Novos Mapas de Afecto. Rio de Janeiro: Jorge Zahar Editor, 2006.p. 7-24.

44. PIKETTY, T. Le Capital au XXI Siècle. Paris: Éditions du Seil,2013.

45. RODRIGUES, C. F. (Org.). Desigualdade Económica em Portugal.Relatório final. Lisboa: ISEG / Fundação Francisco Manuel dos Santos. Disponível em: <http://www.ffms.pt/estudo/19/desigualdade-em-portugal >. Acesso em: 2012.

46. SANTOS, B. S.Portugal: Ensaio contra a autoflagelação. Coimbra: Edições Almedina, 2011.

47. SCALON, C. Justiça como igualdade? A percepção da elite e do povo brasileiro. Sociologias, ano 9, no 18, p. 126-149, jun./dez. 2007.

48. SEN, A.A Ideia de Justiça. Coimbra:Edições Almedina, 2009.

49. SOUZA, J. A Parte de Baixo da Sociedade Brasileira. Revista Interesse Nacional,v. 14, p. 33-41, 2011.

50. STEHR, N. Knowledge Societies.Londres: Sage, 1994.

51. WRIGHT, E. O. Class Counts: Comparative Studies in Class Analysis.Cambridge: Cambridge University Press, 1997.

52. WRIGHT, E. O. Classes. London: Verso, 1985.

53. WRIGHT, E. O. Class, Crisis and the State.London: Verso, 1978.

Recebido em: 01/04/2014

Aceite final: 18/07/2014 